\title{
Eco-friendly dyeing of wool and nylon using madder as a natural dye: kinetic and adsorption isotherm studies
}

\author{
M. Sadeghi-Kiakhani
}

Received: 30 January 2014/Revised: 6 December 2014/Accepted: 27 January 2015/Published online: 10 March 2015

(C) Islamic Azad University (IAU) 2015

\begin{abstract}
In this study, dyeing, fastness and adsorption isotherm characteristics of madder natural dye on the wool and nylon yarns were investigated. Wool and nylon were first mordanted by aluminum sulfate, dyed with natural dye extracted from madder root, and the rates of dyeing and equilibrium times were determined and compared. Nylon, indeed, showed higher dyeing rate and reached equilibrium at comparatively lower times. Adsorption isotherms were identified to be a Nernst-type substrate. In addition, the affinity $\left(\Delta \mu^{\circ}\right)$, free energy $\left(\Delta H^{\circ}\right)$ and entropy $\left(\Delta S^{\circ}\right)$ of madder on the wool and nylon were calculated. The obtained results from thermodynamic data indicated that with temperature rise, the partition ratio and the standard affinity significantly decreased. The affinity of madder natural dye to the nylon was gradually higher as compared with wool. Wool, indeed, displayed higher negative values for both enthalpy and entropy changes as compared to those values of nylon. The colorimetric and fastness properties of madder natural dye on nylon were overall superior than on wool.
\end{abstract}

Keywords Madder - Wool $\cdot$ Nylon · Dyeing $\cdot$ Adsorption isotherm

\section{Introduction}

Many years ago, natural resources are used in the dyeing of textiles all around the world. After the discovery of the first synthetic dye in 1856 and its industrialization in the late of

M. Sadeghi-Kiakhani $(\bowtie)$

Department of Organic Colorants, Institute for Color Science

and Technology, Tehran, Iran

e-mail: sadeghi-mo@icrc.ac.ir nineteenth century, the producers preferred using the synthetic dyes due to their ability to easily match a favorite color, extensive gamut, high purity, economical and easy processing (Ester et al. 2004; Ali et al. 2007; Kasiri and Safapour 2014). For these reasons, the traditional use of natural dyes was vanished in practical and the traditional methods of dyeing with natural dyes have been almost forgotten. Recently, with increasing the number of research laboratories which study on traditional dyeing methods, dyeing of textiles using natural dyes is further considered because of environmental issues. Natural dyes, indeed, are eco-friendly and exhibit better biodegradability with higher environment compatibility (Shahid et al. 2013; Guesmi et al. 2012).

Red dyes of Madder are durable and desirable, and therefore, a lot of researchers have used madder in natural dyeing of textiles. There are 23 organic components based on anthraquinone chemical structures in the madder dye, which contained mostly hydroxyl groups, and in some cases, carboxyl groups, and the madder color strength is related to them (Santis and Moresi 2007; Shams-Nateri 2011). Among them, fifteen groups have color strength, and this is of great importance in fastness properties of the color standpoint (Shams-Nateri 2011; Derksen et al. 2004). Two important samples of these anthraquinone derivatives are shown in Fig. 1. Each kinds of the madder have special type and quantity of anthraquinone structures, which depended on the breed and age of plant. Therefore, by the determination of type and quantity of these components, the madder plant species can be somewhat discovered. It was indicated that alizarin compound is present in the root of madder, and the most important properties of alizarin are to complex with various metallic mordants in dyeing process and produce lac colors, which are not soluble in a weak acid and alkali media (Clementi et al. 2007; Mech et al. 2014). 
<smiles>[X]c1cc(O)c(O)c2c1C(=O)c1ccccc1C2=O</smiles>

Fig. 1 Chemical structure of Alizarin $(\mathrm{X}=\mathrm{H})$ and Porpurine $(\mathrm{X}=\mathrm{OH})$

The dyeing process contained the distribution of the dye between two phases (dye bath and textiles), and obviously in such cases, the thermodynamic behavior, temperature of dyeing process, adsorption isotherms and rate of dyeing can be very helpful for optimal dyeing process (Zollinger 2003; Bird and Boston 1975). The curves obtained from the absorbed dye by the textile surface against the dye concentration in solution at constant temperature give the information about the adsorption isotherms. Adsorption isotherms of a dye, indeed, show the changes of the concentration of the dye in the dye bath at the constant temperature (Rattee and Breuer 1974; Cegarra et al. 1993).

To our best knowledge, sparse data are available in the published literatures concerning the adsorption isotherm and thermodynamic characteristics of the dyeing process of wool and nylon using madder root natural dye. Thus, the aim of this study was to investigate the adsorption isotherm and thermodynamic characteristics of adsorption of the madder root natural dye on the wool and nylon substrates. The results obtained from two substrates were then compared with each other. Furthermore, the fastness and colorimetric properties of the madder on the wool and nylon were analyzed and compared. We hope, the results obtained in this study could be helpful to those who are active in this field, thereby to improve the quality of the wool and nylon dyed by the madder plant natural dye and to inspirit natural color dyeing in the entire world.

\section{Materials and methods}

Mill scoured $100 \%$ wool yarn (434/2 denier), and multifilament nylon yarn (68 monofilament) with 210 denier was supplied by Iran Merino and Alyaf Nakh Co., respectively. The Madder dye was prepared from Yazd province, Iran, and all chemical reagents used for preparation of buffer solutions were of analytical grade from Merck. All solutions were prepared with distilled water.

Spectrophotometric measurements were performed on a UV-Vis Cecil 9200 double beam spectrophotometer. The reflectance characteristics of the dyed samples were measured on a Gratig Macbeth 7000 A, color eye reflection spectrophotometer (D65 illumination, $10^{\circ}$ observer). The $\mathrm{pH}$ was measured with a Metrohm model $691 \mathrm{pH} / \mathrm{mV}$ meters.

\section{Scouring method}

Nylon yarns were first scoured with $0.5 \%$ nonionic detergent at $60{ }^{\circ} \mathrm{C}$ for $30 \mathrm{~min}$ (Sadeghi-Kiakhani et al. 2011). Wool yarns were treated with a solution containing $2 \mathrm{~g} / \mathrm{L}$ nonionic detergent and $1 \mathrm{~g} / \mathrm{L}$ sodium carbonate at $70^{\circ} \mathrm{C}$ for $30 \mathrm{~min}$ (Farizadeh et al. 2010). The liquor ratio (L:R) of the scouring bath for both yarns was 40:1. Then, the yarns were thoroughly rinsed and dried at ambient temperature.

Mordanting procedure

According to research reported in line with textile dyeing by natural dyes, the dyed textiles with natural dyes are not stable enough (Forouharshad et al. 2013; Saravanan et al. 2012). Therefore, it is necessary to enhance the fastness properties of textiles dyed with natural dyes, the common method being the use of a proper mordant. In this research, the aluminum sulfate (alum) as a mordant was used, and the scoured yarns were mordanted prior to dyeing at boiling temperature for $60 \mathrm{~min}$. The concentration of mordant was $5 \%$ owf (on weight of the fiber), $\mathrm{pH}$ was adjusted using acetic acid at 5, and L:R was 40:1. After mordanting, the yarns were removed, thoroughly rinsed with tap water, squeezed and dried.

\section{Extraction of dye}

A weighed amount of dried madder root was extracted with distilled water using laboratory HT dyeing machine. In the standard procedure, the mass ratio of madder plant to the volume of liquid was 1:20; extraction was performed nearly at $100{ }^{\circ} \mathrm{C}$ for $120 \mathrm{~min}$. Then, the solution was filtered by filter paper, so that the obtained solution was absolutely clear.

The dyeing behavior of wool and nylon with madder was investigated using UV-Vis spectrophotometer. The absorption spectra of dye solutions were recorded within the visible spectrum between 400 and $700 \mathrm{~nm}$, and maximum absorption wavelength of the colored solution was identified in $\lambda_{\max }=410 \mathrm{~nm}$. The absorbance of dye solutions before and after dyeing was measured. In order to obtain the amount of the dye in dyeing solution, effluent and wash solutions absorption values were also measured. 
Dyeing

The time of dyeing equilibrium was obtained for considering the dyeing behavior and the adsorption isotherm of madder on the wool and nylon. For this respect, dyeing was carried out in pH 5 at various temperatures of 40,60 and $80{ }^{\circ} \mathrm{C}$ for $150 \mathrm{~min}$. In order to identify the time of dyeing equilibrium accurately, the samples from the dyeing bath solution were withdrawn every $5 \mathrm{~min}$ until to reach equilibrium, and the absorbance of dye solutions was measured. Dye exhaustion was measured by sampling the dye solution before and during dyeing process. The percentage of dye exhaustion $E \%$ was then calculated using the Eq. 1:

$E \%=\frac{A-(C \times D+C \times W)}{A} \times 100$

where $A, C \times D$ represent the absorbance of the dye solution before the dyeing process and after time $t$, respectively. Also, $C \times W$ is concentration of the dye in wash solution.

The rate of dyeing and time of dyeing equilibrium were determined at different temperatures.

To investigate the adsorption isotherm of the madder natural dye on wool and nylon substrates, dyeing processes were performed in equilibrium dyeing time of $150 \mathrm{~min}$. Different concentrations of dye $(0.6,1.2,1.8,2.4$ and $3 \mathrm{~g} / \mathrm{L})$ were prepared, and yarns were then dyed at various temperatures of $40,60,80{ }^{\circ} \mathrm{C}$ keeping L:R at 40:1. Finally, absorption values of dyeing solutions were recorded.

\section{Colorimetric measurements}

The color strength of dyed samples expressed as color strength $(K / S)$ was measured by the reflectance spectrophotometer, and minimum reflection wavelength (maximum absorption wavelength) used for $K / S$ calculations for wool and nylon was 490 and 500, respectively. The relative color strength was calculated by applying the KubelkaMunk (Eq. 2):

$K / S=\frac{(1-R)^{2}}{2 R}$

where $R$ is the decimal fraction of the reflectance of the colored fabrics. $K$ is the absorption coefficient, and $S$ is the scattering coefficient. Color data were analyzed using CIEL $a^{*} b^{*}$ color system. $L^{*}$ defines lightness; $a^{*}$ denotes the red/green value; and $b^{*}$ denotes the yellow/blue value; $C^{*}$ is the saturation value calculated from the reflectance data; and $h^{\circ}$ is hue angle (Wyszecki and Stiles 2000).

Fastness properties

Wash fastness was assessed according to ISO 105 C06 C2S:1994 (E) standard method. Accordingly, washing was conducted at $60{ }^{\circ} \mathrm{C}$ for $30 \mathrm{~min}$, rinsed with cold water, air-dried and analyzed. Light fastness tests were performed according to ISO 105 B02:1988 (E) standard method with xenon arc lamp using blue reference samples. Rubbing fastness tests were carried out using a crockmeter in accordance with the standard method described in ISO 105-X12:1993 (E) (Sadeghi-Kiakhani and Safapour 2014).

\section{Results and discussion}

\section{Dyeing properties}

It is generally accepted that the dyeing process consists of three continuous steps. The first step involves the diffusion of dye molecules to the textile surface and, on the other hand, the migration of dye molecules from the colored solution toward the textile. The second step consists of the adsorption of the dye molecules into the outer layer of the textile. In the latter step, the diffusion of the dye molecules from the textile surface into the textile inside occurs. The second phase, the actual adsorption, is usually quicker than the other two phases, and the diffusion into the textile internal layers is markedly slower than two diffusion phases (Bird and Boston 1975; Kongkachuichay et al. 2002).

To compare the diffusion of madder natural dye into wool and nylon, the rate of dyeing and adsorption equilibrium time were measured at different temperatures and time intervals. The dyeing rates of wool and nylon at 40, 60 and $80{ }^{\circ} \mathrm{C}$ are shown in Fig. 2. The results demonstrated that the $E \%$ and dyeing rate of wool and nylon were steadily increased with increase in temperature. Moreover, dyeing rate of nylon was found to be higher than that of wool. Equilibrium dyeing times at different dyeing temperatures for wool and nylon are given in Table 1. It is observed that with increase in temperature, saturation point occurred at shorter times. Similar trends have been reported in previous studies (Farizadeh et al. 2010; Kim et al. 2005). The reason for this behavior relies possibly on the limited number of sites available (primary amine groups) for dye adsorption in the nylon ( 0.036 equiv $\left.\mathrm{kg}^{-1}\right)$ as compared to that of wool $\left(0.82\right.$ equiv $\left.\mathrm{kg}^{-1}\right)$, resulting in faster saturation of nylon (Lewis and Rippon 2013).

The calculation of equilibrium adsorption isotherm at different temperatures is very important (Farizadeh et al. 2010). Hence, in this research, the standard affinity of the dye $\left(\Delta \mu^{\circ}\right)$, free energy $\left(\Delta H^{\circ}\right)$ and entropy values $\left(\Delta S^{\circ}\right)$ was calculated on both yarns from the amount of dye adsorbed on fibers and the amount of dye remained in dyeing bath at different temperatures $\left(40,60\right.$ and $80{ }^{\circ} \mathrm{C}$ ) and concentrations of dye $(0.6,1.2,1.8,2.4$ and $3 \mathrm{~g} / \mathrm{L})$. 

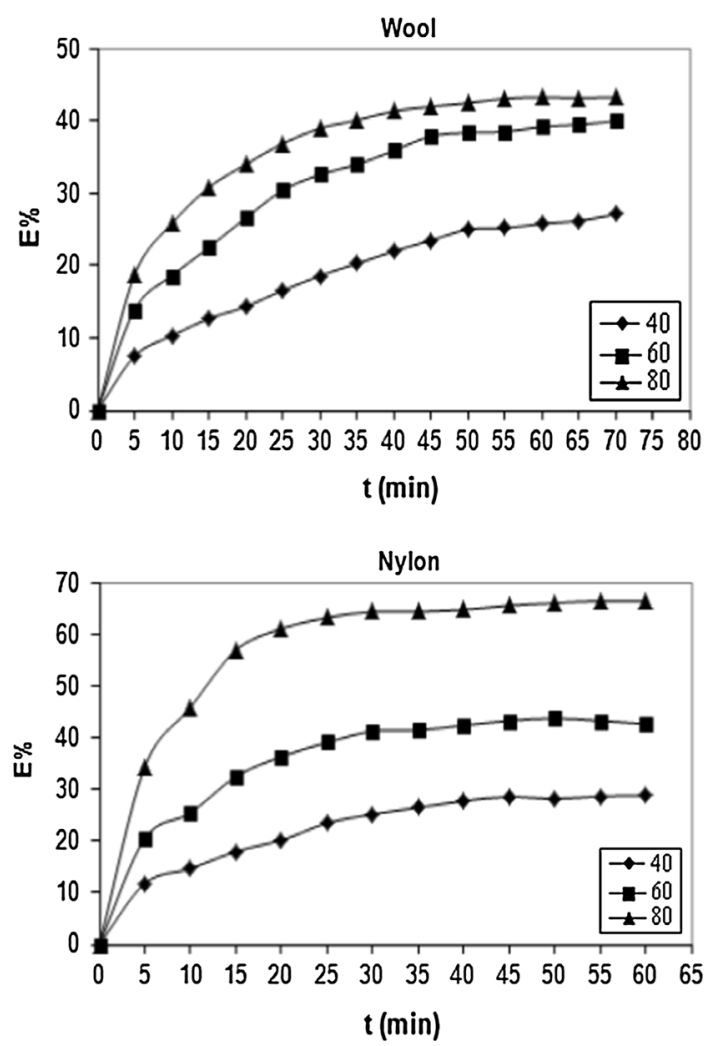

Fig. 2 Rate of dyeing on the nylon and the wool at temperatures of 40,60 and $80^{\circ} \mathrm{C}$ (dye concentration: $3 \mathrm{~g} / \mathrm{L}$ and $\mathrm{pH}$ 5)

Table 1 Time of dyeing equilibrium in wool and nylon fibers (dye concentration: $3 \mathrm{~g} / \mathrm{L}$ and $\mathrm{pH}$ )

\begin{tabular}{llll}
\hline Yarn & \multicolumn{3}{l}{ Temperature $\left({ }^{\circ} \mathrm{C}\right)$} \\
\cline { 2 - 4 } & 40 & 60 & 80 \\
\hline Wool & $60-65$ & $50-55$ & $45-50$ \\
Nylon & $50-55$ & $45-50$ & $40-45$ \\
\hline
\end{tabular}

The most significant thermodynamic parameter is the standard affinity $\left(\Delta \mu^{\circ}\right)$ of the dye in dyeing solution toward textile. This factor is defined as a difference between the chemical potential of the dye in the dyeing solution and the chemical potential of the dye in the textile substrate, in which the obtained rate is the criterion of the affinity of the dye to transfer from dye bath solution toward textile (Kim et al. 2005; Chairat et al. 2005). Prior to reach the saturation point, the relations between $[\text { Dye }]_{\text {solution }}$ and $[\text { Dye }]_{\text {fiber }}$ are assumed to be linear. Therefore, its slope was constant and it yielded a partition ratio $(\mathrm{K})$. Then, the standard affinity was calculated by using the Gibbs free energy (Eq. 3) (Tayade and Adivarekar (2013); Rattanaphani et al. 2007).

$-\Delta \mu^{0}=R T \ln \frac{[D]_{f}}{[D]_{s}}=R T \ln K$

where $R$ is the gas constant $(1.9872 \mathrm{cal} / \mathrm{mol} \mathrm{K}) ; T$ is the absolute temperature $(\mathrm{K}) ;[D]_{\mathrm{f}}$ is the dye concentration in the fiber $(\mathrm{mg} / \mathrm{g}) ;[D]_{\mathrm{s}}$ is the dye concentration in the solution $(\mathrm{mg} / \mathrm{ml})$; and $K$ is the partitioning coefficient.

$[D]_{\mathrm{f}}$ was obtained using the calibration curve established by proper dilutions of stock dye solution $(0.02-0.08 \mathrm{~g} / \mathrm{L})$. The linear regression calibration equation was obtained by computer fitting as follows:

$A=0.11349 * C\left(R^{2}=0.99\right)$

where $A$ is the absorbance; $C$ is the concentration of dyeing solution $(\mathrm{g} / \mathrm{L})$; and linear relationship between absorbance and concentration of dye solution was found.

The affinity of the madder natural dye to the wool and nylon was calculated using isotherm data of dye adsorption at various temperatures of 40,60 and $80^{\circ} \mathrm{C}$, and the results are given in Table 2. It is obviously seen that the equilibrium constant decreased by temperature rise for both yarns. Moreover, the equilibrium constant $(K)$ in the nylon was found to be higher than that of wool at same temperatures. The higher equilibrium constant of the nylon as compared to that of wool indicated higher affinity of madder natural dye toward nylon than to wool.

From Table 2 data, it was also found that the partition ratio and the standard affinity decreased drastically when the temperature increased. These phenomena demonstrated that the adsorption of the madder natural onto nylon and wool was an exothermic reaction process; consequent higher dyeing temperature provided a negative result on the thermodynamic adsorption (Kim et al. 2005; Chairat et al. 2005). Nevertheless, in the practical aspect, since the dyeing process was commonly completed in the restricted period by additional volumes of dyes, higher adsorptions were achieved at higher application temperatures.
Table 2 Partition coefficient $(K)$ and the standard affinity ( $-\Delta \mu^{\circ}$ of concentrations of dye) of madder on wool and nylon

\begin{tabular}{|c|c|c|c|c|c|c|}
\hline \multirow[t]{2}{*}{ Temperature $\left({ }^{\circ} \mathrm{C}\right)$} & \multicolumn{2}{|l|}{$K$} & \multicolumn{2}{|c|}{$-\Delta \mu^{\circ}(\mathrm{cal} / \mathrm{mol})$} & \multicolumn{2}{|l|}{$R^{2}$} \\
\hline & Wool & Nylon & Wool & Nylon & Wool & Nylon \\
\hline 40 & 964.51 & 1,453 & $4,819.82$ & $5,107.24$ & 0.99 & 0.99 \\
\hline 60 & 454.56 & 1,138 & $4,048.98$ & $4,656.19$ & 0.99 & 0.99 \\
\hline 80 & 62.02 & 876.79 & $3,166.21$ & $4,214.37$ & 0.99 & 0.99 \\
\hline
\end{tabular}


(a)

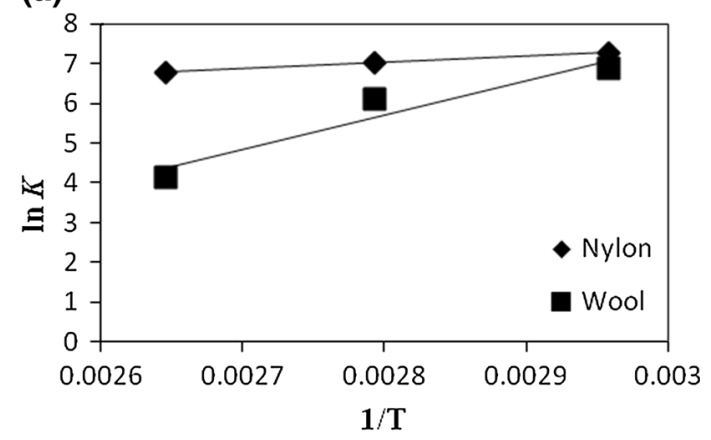

(b)

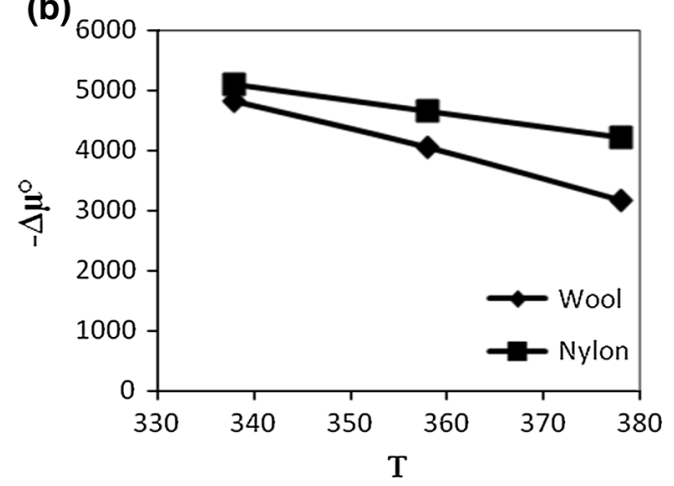

Fig. 3 Relations between $\mathbf{a} \ln k$ and $1 / T$ and $\mathbf{b}-\Delta \mu^{\circ}$ and $T$ [concentrations of dye $(0.6,1.2,1.8,2.4$ and $3 \mathrm{~g} / \mathrm{L})$, at equilibrium dyeing time, $\mathrm{pH}$ 5]

The dye adsorption was an exothermic reaction process, and the amount of exothermic energy depended on the dyeing conditions, such as fibers, dyes, dyeing media and (Kim et al. 2005; Rattanaphani et al. 2007). Furthermore, the enthalpy change $\left(\Delta H^{\circ}\right)$ was considered as the criteria of the adsorption strength of the dye. Meanwhile, the entropy change $\left(\Delta S^{\circ}\right)$ in dyeing indicated the entropy variance of the dye molecules within the yarn (Kongkachuichay et al. 2002; Kim et al. 2005).

The graph of $\ln K$ versus $1 / T$ was plotted (Fig. 3), and from the Eq. 4 , enthalpy change $\left(\Delta H^{\circ}\right)$ was calculated.

$\ln \frac{K_{2}}{K_{1}}=\frac{-\Delta H^{0}}{R}\left(\frac{1}{T_{2}}-\frac{1}{T_{1}}\right)$

The Vant Hoff equation shows the dependency of equilibrium constant with temperature (Rattee and Breuer 1974). Figure 3 showed the relationship between $\Delta \mu$ \% $T$ and $1 / T$ on enthalpy change. As expected from Eq. 4, there was the linear relationship between $\Delta \mu^{\circ} / T$ and $1 / T$. In addition, from the slopes of the straight lines, the enthalpy change can be calculated.

According to Table 3, the heat of wool dyeing process was greater than that of nylon and thus more heating energy is required for dyeing process of wool with madder natural dye. This means that the dyeing was an
Table 3 Reaction heat of dyeing (cal/mol) and entropy (cal/mol K) of madder dye on the wool and the nylon

\begin{tabular}{lllll}
\hline Yarn & $\Delta H^{\circ}$ & $\Delta H^{\circ}$ & \multicolumn{1}{c}{$\begin{array}{l}\circ \\
\left(T_{40}-T_{60}\right)\end{array}$} & $\begin{array}{l}\Delta S^{\circ} \\
\left(T_{60}-T_{80}\right)\end{array}$ \\
\hline Wool & $-7,474.00$ & $-20,498.09$ & -335.15 & -980.66 \\
Nylon & $-2,427.69$ & $-5,181.30$ & -98.83 & -236.97 \\
\hline
\end{tabular}

endothermic reaction and dyeing process was still unfinished; therefore, places for dye molecules adsorption were still available on the yarn and were not yet saturated (Kongkachuichay et al. 2002, Kim et al. 2005). The enthalpy change means that the amount of thermal energy was released when dye molecules were adsorbed into polymer chains. The larger negative value represented that the dye molecules were more embedded between the polymers (Kongkachuichay et al. 2002).

Entropy of dyeing $\left(\Delta S^{\circ}\right)$ was determined from the slope of $\Delta \mu^{\circ}$ versus T plots using Eq. 5 and is given in Table 3 .

$\Delta \mu^{\circ}=\Delta H^{\circ}-T \Delta S^{\circ}$

In most dyeing processes, the entropy change demonstrated negative values. This behavior could be attributed to the adsorbed dyes, which become more restrained inside yarn molecules than the dyeing solution. However, entropy cannot be calculated owing to the complication of dyeing process. The value of the entropy change could be regarded as the ratio of immobility of dyes within the yarns. Therefore, the calculation of this term can be used for comparison purposes. High amount of entropy in the dyeing process demonstrated stronger bonding of yarn with the dye and the more orientation of dye inside the yarn (Kongkachuichay et al. 2002; Chairat et al. 2005). As can be seen from Table 3, the entropy change of nylon is more prominent than that of wool, and this indicated that the dye molecules were more regular inside nylon yarn and thus that was the reason of the better wash fastness of nylon in comparison with wool (see "Fastness evaluation" section). Also, the order of the madder dye within both yarns was enhanced by rise in process temperature, and this amount for nylon was more appreciable than wool.

In Fig. 4, adsorption isotherms of madder natural dye on nylon and wool measured at three different temperatures are shown. It is clearly observed that the dye adsorption rate was strongly influenced by temperature, concentration, adsorbate nature and the nature of adsorbent (Bird and Boston 1975; Rattee and Breuer 1974). Since there was the linear relationship between the dye concentration on the yarns and the dye concentration in the dye bath solution, the suggested adsorption isotherm for madder on the wool and nylon under the investigated condition was inferred to follow the Nernst-type adsorption isotherm. 

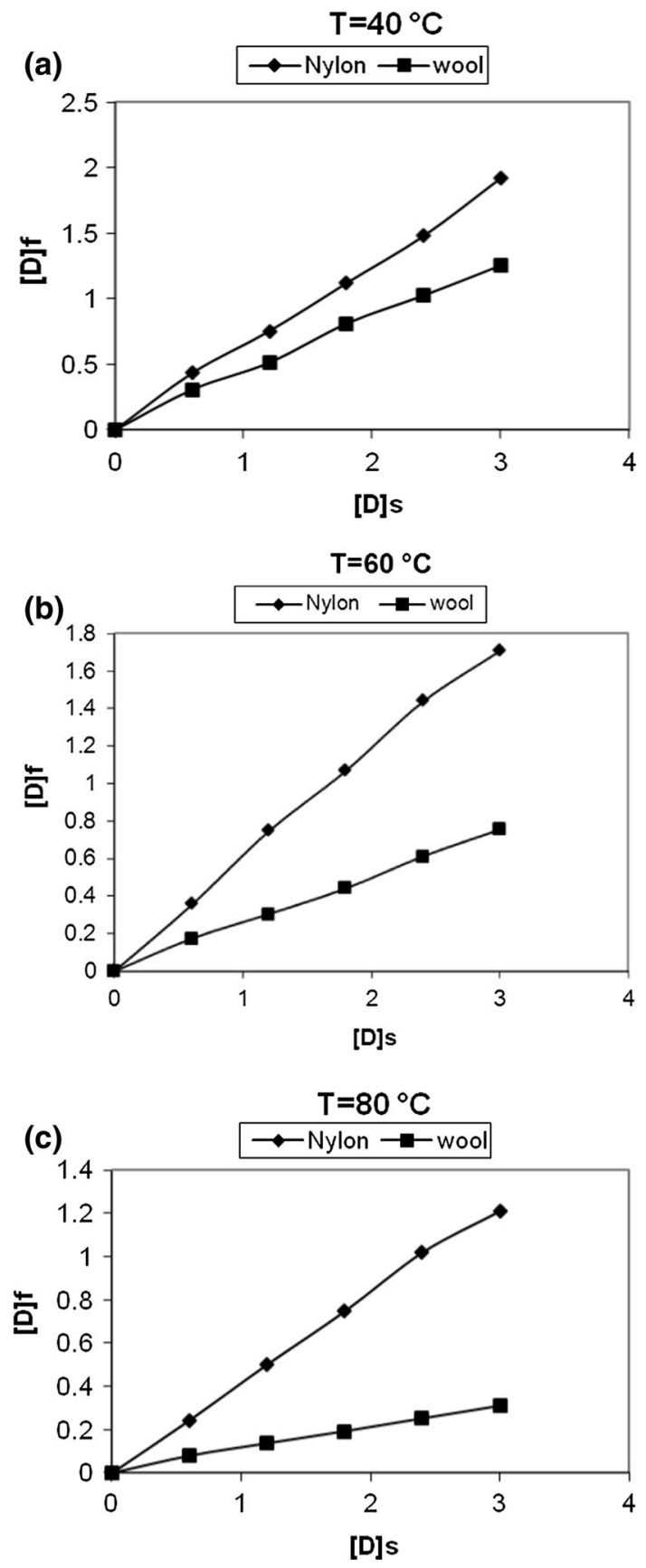

Fig. 4 Madder natural dye adsorption isotherm curves on wool and nylon yarns [concentrations of dye $(0.6,1.2,1.8,2.4$ and $3 \mathrm{~g} / \mathrm{L})$, at equilibrium dyeing time, $\mathrm{pH}$ 5]

\section{Colorimetric properties}

In Fig. 5, the reflectance spectra of wool and nylon yarns in the visible range are shown. As illustrated in Fig. 5, the reflectance values of dyed wool were more than that of

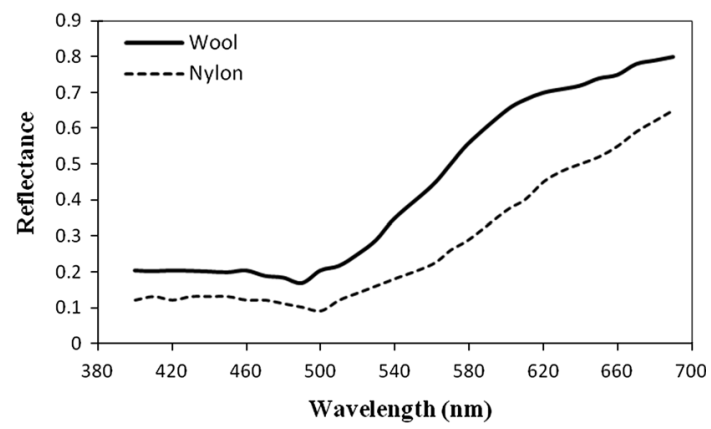

Fig. 5 Reflectance data (dye concentration: $3 \mathrm{~g} / \mathrm{L}, \mathrm{pH}$ 5, T: $80^{\circ} \mathrm{C}$, dyeing time: $60 \mathrm{~min}$ )

Table 4 Colorimetric parameters of dyed wool and nylon using madder dye (dye concentration: $3 \mathrm{~g} / \mathrm{L}, \mathrm{pH} 5, \mathrm{~T}: 80^{\circ} \mathrm{C}$, dyeing time: 60)

\begin{tabular}{llllllll}
\hline Yarn & $L^{*}$ & $a^{*}$ & $b^{*}$ & $C^{*}$ & $h^{\circ}$ & $\lambda_{\max }$ & $K / S$ \\
\hline Wool & 56.29 & 26.88 & 19.78 & 33.37 & 36.34 & 490 & 16.55 \\
Nylon & 49.18 & 27.79 & 20.96 & 34.80 & 37.02 & 500 & 18.44 \\
\hline
\end{tabular}

dyed nylon demonstrating higher color strength of dyed nylon as compared to dyed wool. For better evaluation of dyed yarns, their color quality was reported using the CIE $L^{*} a^{*} b^{*}$ color coordinate. According to Table 4 data, lower lightness $\left(L^{*}\right)$ values were obtained for dyed nylon as compared to dyed wool. Moreover, dyed nylon had higher color strength $(K / S)$ values than dyed wool. In general, higher color strength $(K / S$ values) on the nylon could be attributed to structural features of the dye and yarn. In addition, the electrostatic forces between the positively charged terminal amino groups of the polymeric chains of the yarn and the dye molecules seem to play a dominant role in the increasing of the dyeing ability. As the number of amine groups in the nylon $\left(0.036\right.$ equiv $\left.\mathrm{kg}^{-1}\right)$ is lower than the wool $\left(0.82\right.$ equiv $\left.\mathrm{kg}^{-1}\right)$, the quicker filling of the nylon by the dye molecules is reasonable (Lewis and Rippon 2013).

\section{Fastness evaluation}

The results of fastness tests of madder natural dye on wool and nylon substrates are given in Table 5. Good-to-excellent (4-5) washing fastness was obtained for both dyed substrates. The nylon, in fact, exhibited better rubbing fastness properties than the wool. Moreover, light fastness of the samples was in the range of 4-5 (fair) according to the blue scale standard, and there was not much difference 
Table 5 Fastness properties of madder dye on wool and nylon yarns (dye concentration: $3 \mathrm{~g} / \mathrm{L}, \mathrm{pH} 5, \mathrm{~T}: 80^{\circ} \mathrm{C}$, dyeing time: 60 )

\begin{tabular}{lllllllll}
\hline Yarn & \multicolumn{2}{l}{ Wash fastness } & & & \multicolumn{2}{l}{ Light } & & \multicolumn{2}{l}{ Rub fastness } \\
\cline { 2 - 3 } & Color change & $C^{*}$ & & $N^{*}$ & Fastness & & Dry & Wet \\
\hline Wool & 5 & 4 & $4-5$ & $4-5$ & & $4-5$ & 4 \\
Nylon & 5 & $4-5$ & $4-5$ & 5 & & $4-5$ & $4-5$ \\
\hline
\end{tabular}

$C^{*}$ : staining on the cotton; $N^{*}$ : staining on the nylon

between two dyed samples. In all cases, fastness properties of nylon were higher than wool which may be attributed to better arrangement of dye molecules within fiber polymeric structure as well as more compact structure of nylon, which makes hard scrubbing out of the dye molecule (Guesmi et al. 2012; Shams-Nateri 2011).

\section{Conclusion}

Adsorption isotherms of madder root natural dye on wool and nylon were investigated. Nernst-type adsorption isotherm was obtained. The partition ratio $(K)$, the standard affinity $\left(\Delta \mu^{\circ}\right)$, the heat of dyeing $\left(\Delta H^{\circ}\right)$ and the entropy of dyeing $\left(\Delta S^{\circ}\right)$ were determined. It was found that the adsorption of madder natural dye on wool and nylon was an exothermic process. The standard affinity of wool was gradually higher than nylon. In the case of enthalpy change and entropy change, wool showed higher negative values, while nylon showed lower negative values. For both yarns, as the temperature increased, the rate of dyeing also increased, and nylon had higher dyeing rate than wool. The reflectance spectra of wool and nylon yarns indicated that the color strength of dyed nylon was higher than that of dyed wool. Fastness properties of nylon were overall superior than those of wool. Generally, the results of this study showed that the dyeing and fastness properties of madder natural dye on the both of nylon and of wool yarns were acceptable.

Acknowledgments The author is thankful to Dr. Mohamad Esmail Yazdanshenas for his valuable discussion and suggestions. Also, Institute for Color Science and Technology, Tehran, and Tabriz Islamic Art University, Tabriz, are gratefully acknowledged for all the supports throughout this study.

\section{References}

Ali S, Nisar N, Hussain T (2007) Dyeing properties of natural dyes extracted from eucalyptus. J Text Inst 98(6):559-562
Bird CL, Boston WS (1975) The theory of coloration of textile. Dyers Company Publications Trust: distributed by the Society of Dyers and Colourists

Cegarra J, Puente P, Valldeperas J (1993) The dyeing of textile materials. Textile Institute, Manchester

Chairat M, Rattanaphani S, Bremner JB, Rattanaphani V (2005) An adsorption and kinetic study of lac dyeing on silk. Dyes Pigments 64:231-241

Clementi C, Nowik W, Romani A, Cibin F, Favaro G (2007) A spectrometric and chromatographic approach to the study of ageing of madder (Rubia tinctorum L.) dyestuff on wool. Anal Chim Acta 596:46-54

Derksen GCH, Lelyveld GP, Beek TAV, Capelle A, Groot ED (2004) Two validated HPLC methods for the quantification of alizarin and other anthraquinones in Rubia tinctorum cultivars. Phytochem Anal 15:397-406

Ester SBF, Tlulme AN, Mcnab H, Quye A (2004) The natural constituents of historical textile dyes. Chem Soc Rev 33:329-336

Farizadeh K, Yazdanshenas ME, Montazer M, Malek RMA, Rashidi (2010) A kinetic studies of adsorption of madder on wool using various models. Text Res J 80:847-855

Forouharshad M, Montazer M, Roudbari BY (2013) Zirconium Oxychloride as a novel mordant for natural dyeing of wool yarns. Hindawi Publishing Corporation J Text, doi:10.1155/ 2013/565382

Guesmi A, Hamadi NB, Ladhari N, Sakli F (2012) Dyeing properties and colour fastness of wool dyed with indicaxanthin natural dye. Ind Crops Prod 37:493-499

Kasiri MB, Safapour S (2014) Natural dyes and antimicrobials for green treatments of textiles. Environ Chem Lett 12(1):1-13

Kim TK, Son YA, Lim YJ (2005) Thermodynamic parameters of disperse dyeing on several polyester fibers having different molecular structures. Dyes Pigments 67:229-234

Kongkachuichay P, Shitangkoon A, Chinwongamorn N (2002) Thermodynamics of adsorption of laccaic acid on silk. Dyes Pigments 53:179-185

Lewis DM, Rippon JA (2013) The coloration of wool and other keratin fibres. SDC Wiley, Hoboken

Mech J, Grela MA, Szaciłowski K (2014) Ground and excited state properties of alizarin and its isomers. Dyes Pigments 103:202-213

Rattanaphani S, Chairat M, Bremner JB, Rattanaphani V (2007) An adsorption and thermodynamic study of lac dyeing on cotton pretreated with chitosan. Dyes Pigments 72:88-96

Rattee D, Breuer MM (1974) The physical chemistry of dye adsorption. Academic Press, New York

Sadeghi-Kiakhani M, Safapour S (2014) Eco-friendly dyeing of treated wool fabrics with reactive dyes using chitosanpoly (propylene imine) dendreimer hybrid. Clean Technol Environ Policy. doi:10.1007/s10098-014-0855-Z

Sadeghi-Kiakhani M, Gharanjig K, Arami M, Khosravi A (2011) Dyeing and fastness properties of polyamide fabrics using some acid-based monoazo disperse dyes. J Appl Polym Sci 122:3390-3395

Santis DD, Moresi M (2007) Production of alizarin extracts from Rubia tinctorum and assessment of their dyeing properties. Ind Crops Prod 26:151-162

Saravanan P, Chandramohan G, Saivaraj S (2012) A study on ecofriendly natural dye obtained from barks of Ficus religiosa. L on Cotton Fabric. W. J Appl Environ Chem 1(1):30-34

Shahid M, Islam S, Mohammad F (2013) Recent advancements in natural dye applications: a review. J Clean Prod 53:310-331 
Shams-Nateri A (2011) Reusing wastewater of madder natural dye for wool dyeing. J Clean Prod 19:775-781

Tayade PB, Adivarekar RV (2013) Adsorption kinetics and thermodynamic study of Cuminum cyminum L. dyeing on silk. J Environ Chem Eng 1:1336-1340
Wyszecki G, Stiles WS (2000) Color science concepts and methods, quantitative data and formulae. Wiley, Hoboken

Zollinger H (2003) Colour chemistry: synthesis, properties and application of organic dyes. Wiley, Hoboken 